\title{
Artelogie
}

Recherche sur les arts, le patrimoine et la littérature de l'Amérique latine

$4 \mid 2013$

Fêtes et célébrations en Amérique latine

\section{Dossier "Fêtes et célébrations en Amérique Latine" : estética como eixo transversal, em abordagens políticas, antropológicas e históricas}

Cleusa Maria Graebin e Nádia Maria Weber Santos

\section{(2) OpenEdition}

Edição electrónica

URL: https://journals.openedition.org/artelogie/5886

DOI: 10.4000/artelogie.5886

ISSN: 2115-6395

Editora

Association ESCAL

Refêrencia eletrónica

Cleusa Maria Graebin e Nádia Maria Weber Santos, «Dossier "Fêtes et célébrations en Amérique Latine" : estética como eixo transversal, em abordagens políticas, antropológicas e históricas», Artelogie [Online], 4 | 2013, posto online no dia 02 fevereiro 2013, consultado o 01 dezembro 2021 URL: http://journals.openedition.org/artelogie/5886 ; DOI: https://doi.org/10.4000/artelogie.5886

Este documento foi criado de forma automática no dia 1 dezembro 2021.

Association ESCAL 


\title{
Dossier "Fêtes et célébrations en Amérique Latine" : estética como eixo transversal, em abordagens políticas, antropológicas e históricas
}

\author{
Cleusa Maria Graebin e Nádia Maria Weber Santos
}

Bandeiras coloridas, fogos de artifício, melodias, cores, aromas, sabores interpelam nossas memórias e nos remetem a vivências e experiências : é tempo de festejar !(Cleusa

Graebin)

1 Qual festa? Qual comemoração? Quais ritos e formas de comemorar ? Diversas foram as "entradas" para a composição desse dossiê, uma vez que festas e comemorações são fenômenos socioculturais presentes em qualquer sociedade e, ao estudá-los, entramos em diálogo, também, com a materialidade e imaterialidade da experiência humana, com a vida em movimento, com o conteúdo humano que de tempos em tempos é celebrado.

2 Tratar de festas e comemorações é adentrar um fértil campo para análises sobre as sensações, as emoções, as crenças, os símbolos, os ritos, as vivências e experiências, os costumes, os sonhos, as desilusões e esperanças, as representações e as memórias que, entre outros, nos remetem para sensibilidades e sociabilidades. Todas as festas possuem, também, sua dimensão estética, pois fazem parte das mesmas as formas, as cores, a música, os artefatos, a performance que dá ao conjunto plástico, um aspecto dramático. Assim como há ideias estetizadas, apresentadas de maneira sensível, em cada manifestação festiva.

Porém, nem todos os pesquisadores investigam as festas exclusivamente do ponto de vista estético, como lembra um dos grandes estudiosos no Brasil das festas do Espírito Santo, José Reginaldo dos Santos Gonçalves. Porém, mesmo que os olhares dos pesquisadores transitem por temáticas expressamente delimitadas, que os 
organizadores das festividades se apoiem em saberes herdados, construídos, ressignificados e reconstruídos, a categoria "arte", no contexto das diferentes festas e comemorações, assume significados, ao mesmo tempo, inerentes e transcendentes a cada uma. Quando se brinca o boi, quando mouros e cristãos entram na arena, quando o terno de reis passa nas residências, quando los diablos adentram as ruas em cidades argentinas, bolivianas, panamenhas, equatorianas, entre outras, estão presentes também, artesãos, artistas plásticos locais, músicos, teatreiros... Ou seja, no resultado da atividade humana presente nas festas e celebrações, da natureza que forem, encontra-se, implícita ou explicitamente, a estética. Festejar, comemorar é uma arte, no sentido mais amplo do termo.

4 As festas e comemorações podem ser entendidas ainda, como patrimônio cultural ${ }^{1}$. De acordo com a Convenção para a Salvaguarda do Patrimônio Cultural Imaterial, aprovada pela UNESCO em 17 de outubro de 2003, entende-se por `Patrimônio Cultural Imaterial' as práticas, representações, expressões, conhecimentos e técnicas - junto com os instrumentos, objetos, artefatos e lugares que lhes são associados - que as comunidades, os grupos e, em alguns casos, os indivíduos reconhecem como parte integrante de seu patrimônio cultural. Este Patrimônio Cultural Imaterial, que se transmite de geração em geração, é constantemente recriado pelas comunidades e grupos em função de seu ambiente, de sua interação com a natureza e de sua história, gerando um sentimento de identidade e continuidade, contribuindo assim para promover o respeito à diversidade cultural e à criatividade humana.

5 A partir desta conceituação, constata-se, então, que por patrimônio imaterial entendese o conjunto dos processos de criação e manutenção do conhecimento sobre o seu produto $^{2}$, em detrimento do seu resultado, embora este seja sua expressão material.

6 Considerar as festas como patrimônio imaterial, é reconhecer os seus significados específicos e o seu universo de sentidos em espaços historicamente datados. Parafraseando Paulo Freire, é considerá-las como um instrumento-chave para a leitura de mundo e para a comunicação com o Outro. É tomar contato com as experiências que possibilitaram o pensar e o interpretar coletivo de uma realidade, oportunizando reconstituições de significados, elaborações motivadoras do fortalecimento de identidades culturais.

7 As festas ${ }^{3}$ propiciam acomodação de elementos internos do grupo, promovendo nos sujeitos sociais uma [re]significação cultural, permitindo interações e o estabelecimento de redes de comunicações e contatos. Desta relação resulta o discurso que elaboramos sobre a realidade e sobre nós mesmos, enriquecendo a memória individual e coletiva e seus mecanismos de registro e recuperação.

8 Longe de pensar as festas como tradição ou folclore, congelados em um tempo passado e reproduzidas em um tempo presente, postula-se a historicidade das mesmas (das emoções, sentidos e sentimentos recorrentes), já que a cada edição, mesmo que controladas pelo Estado (calendários cívicos ou turísticos) e pela Igreja (calendário litúrgico), são captadas pelos indivíduos, grupos e até pela sociedade, que faz uso do seu sentido de construção, elaboração da identidade e solidariedade entre os diferentes, a ponto de fazer delas um modo de ação e participação particularmente marcante na sua história.

9 Nas festas, lembranças afloram, comunicam-se em gestos, comportamentos, cores, sabores, odores, sons, vestuário e maneiras de falar. Nesse sentido, as festas podem ser 
entendidas como um refazer constante e coletivo da memória, na medida em que comunidades e grupos recolocam no presente, alguns acontecimentos que a compõem.

As festas têm valor político, pois conservam os traços do simbolismo presente na memória, assinalando a transmissão de bens simbólicos (função pedagógica e unificadora), rupturas de costumes, como forma de resistência e a criação constante de outras formas de dominação, produzindo outros significados e expressões. As festas asseguram a concretização de um contexto que autoriza contato real com códigos e crenças balizadoras da chamada "cultura" de um povo e, em alguns casos, vem a legitimar a cosmovisão constitutiva de um ethos que expressa condições de mobilização, denúncia ou construção.

11 A partir das festas há uma apropriação de espaço e de tempo (profano e sagrado), uma vez que os lugares onde se realizam são tornados públicos, por meio da celebração da memória e do rito que tornam solene a passagem do tempo. o espaço da festa é, também, um espaço plural, permitindo a emergência de múltiplos mecanismos promotores de sociabilidade, bem como evidencia uma prática agregadora de valores que são exaltados sob o signo identitário dos participantes, que comungam os mesmos interesses e expectativas.

12 As festas também podem ser entendidas como linguagens capazes de expressar simultaneamente múltiplos planos simbólicos. Indivíduos, grupos e instituições se comunicam por meio das mesmas : ocorre interação grupal ou comunitária ; relações entre grupos, comunidade e coletividade, a partir das mediações midiáticas; articulação de relações institucionais, no momento em que se decide o que celebrar e com quais parceiros.

13 Ao compreenderem-se as comemorações e as festas das mais variadas sociedades e grupos sociais como narrativas, compõem-se a partir daí verdadeiros conjuntos de sensibilidades que captam as razões e sentimentos de uma temporalidade já escoada, fazendo presente a alteridade do passado, com sua diferença de códigos e valores. As sensibilidades mais finas, as emoções e os sentimentos, devem ser expressos e materializados em alguma forma de registro passível de ser resgatado pelo historiador, segundo Pesavento (2007). Neste sentido, festas e comemorações tornam-se "marcas de historicidade", passíveis de interpretação por parte do historiador. Ou seja, dá-se a ver a historicidade das mesmas também em seus aspectos imateriais (ou mesmo a partir deles).As festas e comemorações podem ser compreendidas e trabalhadas, assim, em seus múltiplos aspectos e em suas muitas funções, tanto em espaços urbanos, como rurais, públicos ou privados. E, também, podem surgir em espaços virtuais (redes sociais) vindo a concretizar-se no espaço público de uma cidade, como por exemplo, nos fenômenos flashmobs, que cada vez ganham mais adeptos nessa era de cybercultura em que vivemos.

14 O marco histórico dos estudos sobre festas, ritos, lendas e outros, no Brasil remonta ao final do século XIX, quando Silvio Romero, influenciado pela Geração de $1870^{4}$, buscava definir o Brasil, compreendendo sua identidade para projetar seu futuro. Os conceitos chave eram identidade nacional e modernização e a construção da brasilidade passava pela narrativa das origens, das chamadas manifestações populares mais genuínas, a fim de esboçar os contornos de uma cultura brasileira, visando uma possível unidade nacional. Assim, empenhado em conhecer o país, Romero aprofundou estudos sobre folclore e etnologia, a partir dos quais publicou Cantos Populares do Brasil (entre $1883 \mathrm{e}$ 1885) e Etnografia Brasileira (1888). O autor abriu caminho para a interpretação 
sociológica do material folclórico em tempos que esse era considerado como curiosidade anedótica. Outro pesquisador da temática foi Veríssimo de Melo que de 1948 a 1996 publicou diversos ensaios e artigos sobre adivinhas, jogos populares, gestos populares, folclore infantil, entre outros.

Preocupado com a crescente urbanização do país e a possibilidade da perda de muitas manifestações populares, Mário de Andrade quando na gestão do Departamento de Cultura da cidade de São Paulo (1935-1938) organizou a Missão de Pesquisas Folclóricas que percorreu o nordeste e o norte do Brasil, em 1938, com os objetivos de mapear fiel e detalhadamente e registrar as manifestações culturais das populações. Ainda é de fundamental importância, lembrar Luís da Câmara Cascudo, o conjunto de seus trabalhos e a obra referência sobre folclore, o Dicionário do Folclore Brasileiro, lançado em 1954.

movimento em prol dos estudos sobre as manifestações populares no Brasil foi reforçado, na década de 1950 e também, nessa década se realizam os primeiros congressos de Antropologia (1953) e Sociologia (1954), interlocutoras próximas aos estudos sobre folclore e que demarcavam os seus campos de atuação.Foi o momento das discussões sobre o Brasil, a partir das obras : Casa-Grande e Senzala (1933), Casa-Grande e Senzala : sobrados e mocambos (1936), ambas de Gilberto Freyre ; Raízes do Brasil (1936) de Sérgio Buarque de Holanda; Populações meridionais do Brasil (1920); Evolução do povo brasileiro (1923); Raça e assimilação (1932) e Formation ethnique du Brésil colonial (1932), de Francisco José de Oliveira Viana. Nesse contexto, os discursos da Sociologia e da Antropologia deixam clara a posição subordinada dos estudos sobre folclore como um ramo da etnologia que se preocupa com as subculturas populares, a saber, mitos, contos, lendas, fábulas, adivinhas, música e poesia, provérbios, adágios, festas, ritos, danças, saberes e fazeres tradicionais, entre outros.

Quanto aos estudos históricos, Francisco Falcon (1996) aponta que a produção historiográfica brasileira foi marcada, nas décadas de 1950 e 1960, pelo que ele explica como dialética da tradição e da inovação. Por tradição, pode-se entender o que se considerava, sob o signo do empirismo positivista, a forma como historiadores, na maioria, autodidatas, escreviam a História a partir de manuais e tratados amplamente aceitos e recomendados pelos eruditos. A inovação se dava com a disseminação dos estudos promovidos pelos intelectuais franceses da Escola dos Anais e da perspectiva teórica marxista. No entanto, a tradição, que dominava as instituições de ensino superior, ditava o que deveria ser ensinado e lido pelos brasileiros. A preocupação era com os grandes fatos, tratados e heróis, a partir dos pressupostos da Escola Metódica Alemã. Ainda, na década de 1960-70, no período da ditadura militar, com o desmantelamento dos cursos de História, a criação do curso de Estudos Sociais, a supressão da disciplina de História e introdução das disciplinas de Educação Moral e Cívica e Organização Social e Política do Brasil, mais se reforçou o ensino de conceitos como nação, pátria, tradição, lei, trabalho e heróis.

Nesse sentido, não era preocupação dos historiadores a temática das festas. Destas e mais das celebrações, ritos, comemorações, folguedos e lendas se ocupavam os estudiosos do folclore.

19 A análise das festas, rituais e tradições populares começa a ter lugar na historiografia brasileira entre os anos 1980 e 1990, influenciados por autores relacionados à Nova História. Um dos seus expoentes, Michel Vovelle, é pioneiro nesse estudo que anteriormente era desenvolvido por folcloristas, antropólogos e etnólogos, como se 
disse acima. Vovelle apontou que as festas não são estruturas fixas, pois existem festas dentro da festa e que mesmo repetidas anualmente ou periodicamente, para além das formas obstinadas, ocorre a flutuação dos elementos, supressão de alguns, incorporação de novos e por vezes, retorno daquilo que havia sido esquecido ou abandonado. As incursões de historiadores brasileiros sobre esta temática exploravam os festejos afrobrasileiros, os de ordem religiosa e indígena em um espaço-tempo - o Brasil colonial. Entre algumas das fontes privilegiadas para o estudo das festas utilizadas pelos historiadores estão os relatos de viajantes, cartas, obras de artes plásticas, obras literárias.

Entre 18 e 22 de novembro de 1992, em Lisboa, Portugal, ocorreu o VIII Congresso Internacional "A Festa", quando Ana Maria da Silva Moura, Maria Beatriz Nizza da Silva e Ronaldo Vainfas apresentaram trabalhos sobre festas coloniais no Brasil. Em 1994, Mary Del Priori lançou a obra "Festas e utopias no Brasil colonial", na qual analisava o que chamou de festas-concessões, as quais eram permitidas e incentivadas pelas autoridades e pela Igreja em Minas Gerais e na Bahia. Estas possuíam função didática, disciplinadora e expressavam o poder do monarca. Em sua análise, Del Priori constatou que setores da sociedade como os dos negros e indígenas subvertiam as normas, reproduzindo suas hierarquias e incluindo seus traços culturais. Em 1999, István Jancsó e Iris Kantor organizaram o Seminário Internacional "Festa : Cultura e Sociabilidades na América Portuguesa", quando pesquisadores brasileiros e portugueses discutiram festas e comemorações relacionadas à construção de identidade nacional, festas religiosas utilizadas pelos jesuítas para a catequese dos indígenas, aquelas que integravam o processo de urbanização no final do século XVII e durante o século XVIII e as que passaram a ocorrer com a vinda da corte real portuguesa para o Brasil e continuaram até a declaração de independência do Brasil. Desse evento resultou obra bibliográfico com o mesmo título, editada em 2001 em dois volumes, tendo em vista o grande volume de textos (49 ao todo).

21 Na década de 2000 algumas das mais importantes obras, consideradas como fontes de pesquisa para os que se debruçam sobre festas, foram reditadas: "Procissões Tradicionais da Bahia", de João da Silva Campos e "Festas e Tradições Populares do Brasil", de Melo Morais Filho. Também, sucederam-se nesta década, encontros, congressos, seminários, dossiês em periódicos científicos, obras bibliográficas que se dedicaram a trabalhar com a temática no país. Um brevíssimo e incompleto balanço de trabalhos acadêmicos (teses e dissertações) produzidos nos Programas de PósGraduação de universidades brasileiras, levantados a partir de consulta ao banco de dados da CAPES, revela um total de 49 produções.

Nos demais países da América Latina, pesquisadores de diferentes campos do saber também se debruçam sobre festas e comemorações, considerando-as alguns, como espetáculos em que se pode distinguir a intenção de impor o poder estabelecido e a de incluir o que é próprio de cada grupo, comunidade, indivíduo, naquilo que lhes é mais profundo, misterioso, próprio de cada ser humano. Outros destacam a dessacralização do mundo, mas a plena vigência da religiosidade popular. Um bom número se dedica a estudar as chamadas fiestas pátrias, que comemoram datas cívicas, entendendo-as como formas de identidade entre passado e presente, abordando enfoques como a construção histórica, aspectos antropológicos, aspectos sociais, ideológicos, seu papel ordenador, pedagógico e disciplinador. Diversos investigadores voltam-se para os estudos das festividades indígenas, analisando o grupo que a partir daquelas se integra, 
proporcionando a continuidade de práticas culturais, reafirmando pertencimentos, proximidade, criação e fortalecimento de vínculos com o sagrado.

Em geral, os marcos temporais desses estudos seguem aqueles discutidos anteriormente a exemplo do Brasil e estão relacionados com o desenvolvimento dos estudos culturais na América Latina. ${ }^{5}$ É profícua, também, a produção de acadêmicos que trabalham e ou estudam nas universidades latino-americanas e nos Estados Unidos que promove agenda de investigação relacionada com políticas de identidade, movimentos sociais e aspectos culturais de minorias.

Assim sendo, é neste múltiplo e diversificado enfoque que escolhemos os textos deste dossiê, que ora apresentamos na Revista Artelogie - Recherches sur les arts, le patrimoine et la littérature de l'Amérique Latine. Os pesquisadores brasileiros e de alguns países da América Latina presenteiam-nos com suas pesquisas e reflexões sobre festas e comemorações em seus variados ângulos e aspectos.Anahi Rocio Pochettino, em seu texto Festiva y neobarroca: Gabriela Bejerman, relaciona a literatura novelística de Bejerman, a partir das festas galantes, com tensões políticas e estéticas da literatura argentina, bem como indaga a utilidade do neobarroco recente, advindo de uma tradição poética modernista, para colocar questões sobre a narratividade do autobiográfico na comparação com as práticas discursivas e imagens utópicas do comunitário.Em uma perspectiva bem diferente, Maria Catarina C. Zanini e Miriam de Oliveira Santos (As Festas da Uva de Caxias do Sul, RS (Brasil): historicidade, mensagens, memórias e significados) analisam o processo histórico da Festa da Uva em uma cidade do sul do Brasil (Caxias do Sul) marcada pela colonização italiana, festividade esta que, no inicio com a finalidade de mostra dos produtos dos colonos da região passa a se constituir, em suas últimas edições, em festividade comemorativa e de construção da memória desses italianos colonizadores, de grande importância na região.Carla Mary de Oliveira e Cláudia Engler Cury, no artigo intitulado A Província em festa : celebrações e poderes simbólicos na visita de sua Majestade Imperial à Parahyba do Norte - 1859, demonstram com maestria, o intricado jogo de poder simbólico entre as elites locais e o poder do Segundo Império, através da reflexão sobre as festas comemorativas na Parahyba do Norte, esta "suspensão da vida corriqueira", que tiveram lugar quando da visita que Dom Pedro II fez na região em 1859. As autoras utilizam-se, para dar conta dessa discussão, não somente de documentos oficiais e jornais, mas também da riquíssima fonte que são as cadernetas de viagem de D. Pedro II. Assim, as festas tornam-se um "patrimônio cultural político" do Segundo Reinado brasileiro, documentados e agora interpretados por historiadores.

Já Gustavo de Castro e Silva e Verônica Brandão, em Celebrando a morte : ritos fúnebres no Brasil, intentam mostrar aspectos dos rituais de celebração da morte em algumas regiões do Brasil. Há toda uma estética presente nos rituais funerários, mescla de elementos indígenas e africanos que festejam o morto em vez de pranteá-lo. A morte é mostrada, segundo o autor, como "espetáculo comemorativo", incorporado aos fatos da vida. O velório é um acontecimento social onde ocorrem encontros de familiares, amigos e de espectadores sem nenhum parentesco ou afinidade com o morto, mas que percorrem velórios para comer, beber, apreciar os ornamentos, as vestimentas, o caixão, as velas e aprender novas piadas, afinal, o defunto tem de partir feliz para a sepultura, a fim de não voltar para assombrar os vivos.

Giuseppe Gatti introduz a releitura de um conto, como fonte e metodologia para trabalhar, em seu artigo El fin de fiesta del Uruguay: la decadencia individual como 
metáfora del declive colectivo en el relato "Bienvenido Bob", de Juan Carlos Onetti, questões sobre o colapso progressivo, social e econômico do Uruguai, através de posicionamentos alegóricos - entre o subjetivo e o coletivo - , isto é, o "fim da festa".

O trabalho de Camila Silva, "São os farrapos que voltam" : o heroísmo farroupilha entre o passado e o futuro do Rio Grande do Sul, nos remete aos componentes simbólicos das comemorações farroupilhas, a partir das narrativas comemorativas em jornais portoalegrenses no primeiro centenário da Revolução Farroupilha, reatualizando o mito e chamando atenção para o fato de que esses periódicos ajudam a construir a memória de um povo e sublinhando as festas e comemorações em seu caráter pedagógico.

No artigo de Maria Cristina Bohn Martins, vemos mais uma vez aspectos políticos e sociais de uma comunidade sendo estetizados pela festa, ou festas, pois em As celebrações, a comunidade e o poder. Os faustos reais de Carlos III e os múltiplos sentidos das festas, a autora argumenta, a partir das celebrações dos Faustos Reais na Missão de São Borja, em seus aspectos simbólicos e ritualísticos, sobre as mudanças ocorridas na redução jesuítico-guarani na segunda metade do século XVIII.

Aspectos diferentes sobre comemorações, mas também atentando a jogos políticos e sociais em comunidades negras, observamos no texto de Martha Abreu e Hebe Mattos (Festas, patrimônio cultural e identidade negra. Rio de Janeiro, 1888 - 2011), ao trabalharem com Jongos em uma pesquisa histórica, no Quilombo São José da Serra (Valença, RJ) e a comemoração de 13 de maio, articuladas com a nova política de patrimônio cultural imaterial no Brasil.

30 Heloisa Capel e Leandro Rocha analisam o povo indígena Chiquitano, fronteiriço entre Brasil/Bolívia, no artigo Dinâmicas Culturais Etnogênicas em Performances Identitárias : a festa dos Chiquitano, e uma de suas manifestações "artísticas", a Festa de inauguração do Memorial Espírito Santo dos Chiquitano, festa de caráter também etnogênico, onde procuram identificar, através dos elementos festivos e performáticos, os processos identitários deste povo.

31 Sob um prisma diverso e profícuo, Nina Graeff nos conduz aos meandros da musicalidade em Samba de Roda : comemorando identidades afro-brasileiras através da performance musical, revelando marcas de historicidade nas práticas musicais afrobrasileiras da região do Recôncavo Baiano, prenhes de significação simbólica e identitária, onde "atividade cotidiana ou ritual, sambar é celebrar a identidade e a memória dos afro-brasileiros".

José Edimar de Souza trabalha a importância no processo educacional e nas práticas pedagógicas, em escolas primárias e a partir da rememoração de professoras do Grupo Escolar de Lomba Grande, da festa cívica (Festa da Pátria), ou o desfile cívico de 7 de setembro, no texto A Festa da Pátria: memórias cívicas na área rural de Novo Hamburgo/RS (1930-1970). O autor contempla vários episódios e reflexões relativas a este patrimônio institucional, utilizando para tanto, depoimentos orais de professoras que vivenciaram muitas das comemorações. Estas, nos seus diferentes ritos e performances têm cunho pedagógico e exercem papel formador e civilizador. Nesse sentido, os elementos estéticos estão presentes para apelar às sensibilidades dos participantes : os cantos orfeônicos, os desfiles cívicos acompanhados por bandas, os poemas recitados, representações sobre grandes personagens históricos, tudo isso a fim de reforçar "uma" identidade nacional e legitimar a república como regime político. 
autora Eliane Fleck contempla este dossiê com texto ancorado nas Cartas Ânuas ${ }^{6}$, as quais, entre outros elementos catequizadores, desvelam registros de uma estética de conversão indígena à cultura ocidental e à religião cristã : muita dança, muita música, muitos elementos antecedentes de nosso carnaval, quiçá. É uma estética barroca. Em $O$ triunfo solene da conversão: "Como em suas maiores festas, preparam os índios os altares com flores e velas de cera silvestre, fazem arcos triunfais, nos quais penduram os pássaros do ar, os animais do mato e os peixes da água, dançam e tocam flautas a seu modo" (Província Jesuítica do Paraguai, século XVII), a historiadora nos faz perceber o quanto os jesuítas perceberam a sensibilidade indígena à música e aos recursos cênicos tornando-se estes, elementos estéticos de conversão. Ao mesmo tempo, os indígenas utilizando a estética como tradução sensível de suas ideias, continuaram a praticar sua religiosidade. A autora chama a atenção para as apropriações e as bricolagens que permitem perceber as reduções jesuítico-guaranis como "espaços de acomodação de sensibilidades".o historiador Artur Cesar Isaia, em Congressos Eucarísticos : Cristo Rei celebrado no Brasil da primeira metade do século XX, interpreta essas celebrações e práticas comemorativas de um Brasil católico como "ocasiões nas quais a celebração maciça do público ao acatamento a Cristo Rei mobilizava a opinião pública, reforçando e pondo em evidência as reservas simbólicas de uma igreja, cuja força política não podia ser desprezada pelos detentores do poder".

opóloga Maria Laura Viveiros de Castro Cavalcanti, em A festa em perspectiva antropológica: carnaval e os folguedos do boi no Brasil, presenteia-nos com um belo texto a respeito destas duas festas, apontando para seus desdobramentos contemporâneos (desfile das escolas de samba e no Rio de Janeiro e o festival dos Bois Bumbás de Parintins, Amazonas). Com isto, a autora afirma que se "configuram universos rituais heterogêneos e complexos", indicando a "ampla variedade e a grande heterogeneidade interna das festas contemporâneas na cultura popular brasileira".

No texto (Em) canto de santo: religiosidade e identidade no Bumba-meu-boi do Maranhão, os autores maranhenses Heridan de Jesus Guterres Pavão Ferreira, Marcelo Nicomedes dos Reis Silva Filho e Claudia Regina Pinto Silva trabalham a Festa do Boi, festejo representativo da população negra deste estado brasileiro e um patrimônio cultural brasileiro. Como festa tradicional reúne várias manifestações culturais e se transforma em uma grande celebração tendo o boi como o centro do universo místico-religioso. Os autores apresentam-na enquanto importante "elemento para construção de identidades e preservação dos valores culturais afro-brasileiros, que se materializam por meio de um diálogo entre a religiosidade e a literatura". A pesquisadora mexicana Rosalina Estrada Urroz, em seu artigo Entre el repique y el estruendo, la celebración del 5 de Mayo en Puebla, 1868-1930, analisa o festejo municipal desta data importante ao México, na vitória em relação à ocupação francesa, como prenhe de simbolismo patriótico: honra dignidade e valentia, mas também prenhe de outros símbolos históricos e seus significados.

Desta forma, os dezesseis artigos desse dossiê compõem uma rede multifacetada de noções, representações e sensibilidades sobre festas e comemorações, tendo a estética como eixo transversal, em abordagens políticas, antropológicas e históricas. Esperamos que o leitor sinta-se instigado a refletir e a dialogar com estes textos, fazendo uma profícua leitura. 


\section{BIBLIOGRAFIA}

A FESTA. Comunicações apresentadas ao VIII Congresso Internacional, vol. I, Lisboa, Sociedade Portuguesa de Estudos do Século XVIII, Universitária Editora, 1992.

CAMPOS, João da Silva. Procissões Tradicionais da Bahia. 2. ed. rev. Salvador : Secretaria de Cultura e Turismo/Conselho Estadual de Cultura, 2001.

DA MATTA, R. Carnavais, malandros e heróis. Rio de Janeiro : Graal, 1980.

DEL PRIORE, M. Festas e utopias no Brasil colonial. São Paulo : Brasiliense, 1994.

DURKHEIM, E. As formas elementares da vida religiosa. São Paulo : Martins Fontes, 2000.

DUVIGNAND, J. Fêtes et civilizations. Paris : Weber, 1973.

GONÇALVES, José Reginaldo Santos ; CONTINS, Marcia. Entre o Divino e os homens : a arte nas festas do Divino Espírito Santo. Horizontes Antropológicos. [online]. 2008, vol. 14, n. 29, p. 67-94.

ISAMBERT, F. Le sens du sacré. Paris : Minuit, 1982.

ITANI, Alice. Festas e calendários. São Paulo : UNESP, 2003.

JANCSÓ, István ; KANTOR, Íris (orgs.). Festa : cultura e sociabilidade na América portuguesa. São Paulo : Imprensa Oficial ; Hucitec ; Edusp ; Fapesp, 2001. 2v. (Coleção Estante USP - Brasil 500 anos, 3).

LEENHARDT, Jacques. Sensibilidade e Sociabilidade. In : RAMOS, Alcides Freire ; MATOS, Maria Izilda Santos de ; PATRIOTA, Rosangela (Org). Olhares sobre a história. Goiás : Editora Ucitec, 2010.MORAIS Fº, Melo. Festas e Tradições Populares do Brasil. Brasília-DF : Senado Federal, 2002.

PESAVENTO, Sandra ; LANGUE, Frédérique. Sensibilidades na História : Memórias singulares e Identidades urbanas. Porto Alegre : Ed. da UFRGS, 2007.

PRIORE, Mary Del. Festas e utopias no Brasil colonial. São Paulo : Brasiliense, 1994.

THOMPSON, E. P. Costumes em comum. Estudos sobre a cultura popular tradicional. São Paulo :

Companhia das Letras, 1998.

VOVELLE, Michel. Ideologias e mentalidades. São Paulo : Brasiliense, $2^{\underline{a}}$ ed., 1991.

\section{NOTAS}

1. Para a elaboração deste item foram consideradas as seguintes fontes : FONSECA, Maria Cecília Londres. 0 patrimônio em processo : trajetória da política federal de preservação no Brasil. Rio de Janeiro : UFRJ/IPHAN, 1997. GONÇALVES, José Reginaldo Santos. A retórica da perda : os discursos do patrimônio cultural no Brasil. Rio de Janeiro:UFRJ, 1996. GUARNIERI, W. R. Conceito de cultura e sua inter-relação com o patrimônio cultural e a preservação. Cadernos Museológicos, IBPC, Rio de Janeiro, n. 3, 1990. Legislação brasileira sobre patrimônio imaterial.

2. Grifo das autoras.

3. A construção conceitual sobre festas e comemorações apoiou-se em obras de : DA MATTA, 1980 ; DEL PRIORE, 1994 ; DURKHEIM, E. 2000 ; DUVIGNAND, J., 1973 ; ITANI, 2003 ; ISAMBERT, 1982 ; MORAES FILHO, 2002 ; THOMPSON, E. P., 1998. A construção conceitual sobre festas e comemorações apoiou-se em obras de : DA MATTA, 1980 ; DEL PRIORE, 1994 ; DURKHEIM, E. 2000 
; DUVIGNAND, J., 1973 ; ITANI,, 2003 ; ISAMBERT, 1982 ; MORAES FILHO, 2002 ; THOMPSON, E. P., 1998.

4. Escritores brasileiros que, esteticamente, romperam com o modelo de arte romântica, concebendo a literatura como veículo de divulgação das novas ideias vinculadas à ideologia liberal, positivismo e determinismo biológico. Ver : MORA, Maria Aparecida Resende. Silvio Romero : dilemas e combates no Brasil da virada do século XX. Rio de Janeiro : Ed. FGV, 2000 ; CANDIDO, Antonio. Literatura e sociedade. São Paulo: T. A. Queiroz, 2000.

5. Sobre a entrada dos estudos culturais na América Latina ver : DICCIONARIO de estudios culturales latino-americanos. México : Siglo XXI Editores ; instituto Mora, 2009.

6. As Cartas Ânuas eram documentos internos da Companhia de Jesus os quais eram dirigidos ao Superior Geral da congregação em Roma. Relatavam os acontecimentos anuais ocorridos nas diferentes missões dirigidas pelos jesuítas. As Ânuas da Província do Paraguay, região que abarcava parte do Rio Grande do Sul (Brasil), como também parte dos atuais territórios do Uruguai, Argentina e Paraguai, começaram a circular a partir de 1609, encerrando-se com a expulsão dos jesuítas em 1750. Essas cartas eram manuscritas e alcançavam em média, 150 a 170 páginas. São fontes potenciais para a reconstrução da história da Bacia Platina e das Missões Jesuíticas.

\section{RESUMOS}

Qual festa? Qual comemoração? Quais ritos e formas de comemorar? Diversas foram as "entradas" para a composição desse dossiê, uma vez que festas e comemorações são fenômenos socioculturais presentes em qualquer sociedade e, ao estudá-los, entramos em diálogo, também, com a materialidade e imaterialidade da experiência humana, com a vida em movimento, com o conteúdo humano que de tempos em tempos é celebrado.

Quelles fêtes, quels rites et comment les célébrer? Plusieurs entrées étaient envisageables pour aborder ce dossier dans la mesure où les fêtes et les célébrations sont des phénomènes socioculturels présents dans toute société. En les analysant, nous participons au dialogue entre la matérialité et l'immatérialité de l'expérience humaine, celui de la vie en mouvement qui se déplace au rythme des célébrations successives. Travailler avec un tel sujet (fêtes et célébrations), c'est aussi explorer un champ fertile pour l'analyse des sensations, des émotions, des croyances, des symboles, des rituels, mais aussi des expériences, des habitudes, des rêves, des déceptions et des espoirs. La mémoire et les représentations, en relation étroite avec les sensibilités et la sociabilité, nous rappelent les liens intimes que les expressions esthétiques ont dans toute manifestation festive.

\section{AUTORES}

\section{CLEUSA MARIA GRAEBIN}

Coordenadora e professora do PPG em Memória Social e Bens Culturais - UNILASALLE/CanoasRS/Brasil ; Diretora do MAHLS (Museu e arquivo histórico La Salle) ; editora chefe da Revista Mouseion do Unilasalle. 


\section{NÁDIA MARIA WEBER SANTOS}

Professora do PPG em Memória Social e Bens Culturais - UNILASALLE/Canoas-RS/Brasil ; editora da revista Mouseion do Unilasalle ; membro do Comitê científico do GT Nacional de História Cultural da ANPUH. 